\title{
Soil moisture, field-scale toposequential position, and slope effects on yields in irrigated rice (Oryza sativa L.) fields in Honduras
}

\author{
Kyle M. Earnshaw ${ }^{1}$, Blair Orr ${ }^{2^{*}}$ \\ ${ }^{1}$ Department of Forestry and Natural Resources, Purdue University, West Lafayette, USA \\ ${ }^{2}$ School of Forest Resources and Environmental Science, Michigan Technological University, Houghton, USA; \\ *Corresponding Author: bdorr@mtu.edu
}

Received 19 May 2013; revised 19 June 2013; accepted 15 July 2013

Copyright (C) 2013 Kyle M. Earnshaw, Blair Orr. This is an open access article distributed under the Creative Commons Attribution License, which permits unrestricted use, distribution, and reproduction in any medium, provided the original work is properly cited.

\begin{abstract}
Rice (Oryza sativa L.) is an important cash crop in Honduras. The availability of inexpensive irrigation in the study area (Flores, La Villa de San Antonio, Comayagua) encourages rice farmers to neglect prescribed methods of soil and water conservation, such as land leveling, puddling, and soil bunds. This study looked at the effect of failure to mitigate water loss on sloping fields. Soil moisture (Volumetric Water Content) was measured using a soil moisture probe after the termination of the first irrigation within the tillering/vegetative, panicle emergence/flowering, post-flowering/pre-maturation and maturation stages. Yield data were obtained by harvesting on $1 \mathrm{~m}^{2}$ plots in each soil moisture testing site. Data analyses looked at the relationship between yield and slope, soil moisture, farmers, and toposequential position along transects. Toposequential position influenced yields more than slope and soil moisture was not a significant predictor of yields. Irrigation politics, high water inputs, and land tenure were proposed as the major reasons for this result.
\end{abstract}

Keywords: Land Tenure; Prices; Comayagua; Soil Bunds; Precipitation

\section{INTRODUCTION}

For optimal rice production, rice farmers must balance agronomic requirements of rice varieties with site conditions, finances, infrastructure (i.e. tractor and irrigation availability) and politics (i.e. national price agreements and local labor availability). Nevertheless, the most im- portant resource input for rice production is water [1]. In order to limit water stress in rice, farmers throughout the world commonly grow rice under flooded conditions. Seventy-five percent of world production of rice, as of 2001, came from irrigated systems [2]. However, in areas where water is scarce, unpredictable, or expensive, farmers employ a variety of strategies for maximizing water use efficiency or water productivity, calculated as grain weight produced per water used or grain weight per water provided through irrigation and precipitation $[3,4]$. Growing rice under aerobic conditions or using alternate wetting and drying and saturated soil culture technologies has been increasingly used and implemented with variable success, but studies have shown that they offer opportunities for producing rice with small decreases in production but large savings in water [5-8]. Aerobic rice refers to rice grown in non-flooded and non-saturated conditions [4]. Alternate wetting and drying systems allow fields to drain midway through the rice growing season and allow for periodic drying of the soil after panicle initiation [9]. Saturated soil culture refers to nonflooded systems in which the soil is maintained at constant saturated levels [5,10]. Land leveling and water conservation structures, regardless of the cultural practice utilized, improve water use efficiency by providing the entire field with similar conditions and limiting water loss through percolation, runoff, and seepage [1], which are estimated to account for $50 \%-80 \%$ of total water use in rice fields [11]. In sloping fields, the losses are expected to be higher and yields should vary more throughout the field.

Rice farmers in the semi-arid Irrigation District of Flores, Comayagua, Honduras rarely prepare their fields and manage water on-field using recommended methods. They rely on negotiated prices, cheap irrigation water, and precipitation to generate a profit. Rice is grown 
during the rainy season with water inputs coming from precipitation and irrigation, usually applied every $8-10$ days. Planting, fertilization, weeding, and irrigation are done by hand and land preparation and harvesting are done mechanically with disk plows and combines, respectively. The farmers do not level their fields or install soil bunds along the contour to maintain equal soil moisture throughout the field. Because the farmers rarely install soil bunds at the downslope end of the fields, much of the irrigation water, moreover, runs off the field without providing any productive benefit to the field. On flat fields, these practices should have little or no impact on yields, but on sloping fields, given rice's sensitivity to water stress, they should cause wider disparities between soil moisture levels at the high and low ends of fields, consequently causing correlative yield disparities. On sloping fields, the high sides of the fields dry out more quickly, encouraging weed growth because a sparse rice canopy and herbicide runoff, experience more frequent water stress, and have lower yields relative to the lower end of the field where water and fertilizers would be higher [12].

This study was designed to determine 1) if fields with higher slopes had lower yields than fields with lower slopes, 2) if yields were higher downslope relative to upslope, and 3) if yield disparities on and between fields were correlated with soil moisture differences throughout the growing season and soil moisture differences during five rice growth stages.

\section{METHODS}

\subsection{Site and Field Description}

The study took place in 2010 in Flores, municipality of La Villa de San Antonio, Department of Comayagua, Honduras $\left(14^{\circ} 17^{\prime} 38.81^{\prime \prime} \mathrm{N}, 87^{\circ} 34^{\prime} 17.82^{\prime \prime} \mathrm{W}, 680\right.$ m.a.s.l.). The fields used in this study were within the Irrigation District of Flores, which contains about $69 \mathrm{~km}$ of primary and secondary canals providing water from the El Coyolar dam $\left(14^{\circ} 19^{\prime} 12.17^{\prime \prime} \mathrm{N}, 87^{\circ} 30^{\prime} 42.02^{\prime \prime} \mathrm{W}, 823\right.$ m.a.s.1.) to an area of about 2,300 hectares. The Irrigation District is managed by the Association of Irrigation Farmers of Flores and the Honduran Department of Agriculture and Livestock. The Department of Natural Resources manages the El Coyolar dam in conjunction with the participating parties of the Irrigation District of Flores.

The study used five rice fields, farmed by two farmers. The farmers were chosen because they were respected in the District and rented large areas, allowing for fields with a variety of slopes to be chosen, most of which would be planted, irrigated, and harvested concurrently. From the fields rented by Farmer 1 and Farmer 2, individual fields were chosen, ranging in slope from $0.5^{\circ}$ - $6^{\circ}$. Where possible, the study used adjoining fields to limit soil and management differences. The three fields of Farmer 1 were adjoining. The two fields of Farmer 2 were about five kilometers away from Farmer 1's fields and 0.5 kilometers apart from each other because we wanted to include a field with a slope between $4^{\circ}-6^{\circ}$.

Farmer 1 planted his rice on 9 June, 2010 and harvested on 20 October, 2010, 134 days after planting. Farmer 2 planted his rice on 5 July, 2010 and harvested on 20 November, 2010, 139 days after planting.

The average precipitation from 1972 to1986 in Flores was $876 \mathrm{~mm} \cdot$ year $^{-1}$ [13]. During the year of the study, data given to the lead author by an agronomist from a nearby farm owned by Ingeneria Agrícola y Ganadera S.A. showed that Flores received $1479 \mathrm{~mm}$ of precipitation. During the five months that Farmer 1 had his rice planted, from June to October, precipitation averaged $207 \mathrm{~mm} \cdot \mathrm{month}^{-1}$. From July to November, the five months of cultivation for Farmer 2, precipitation averaged $198 \mathrm{~mm} \cdot \mathrm{month}^{-1}$. During the three key months for rice development in this study, from July through September, precipitation averaged $300 \mathrm{~mm} \cdot \mathrm{month}^{-1}$.

\subsection{Field Characterization}

Size, slope, and general soil characteristics were determined for each field. The size was measured in ArcGIS using GPS points taken on a Garmin $72 \mathrm{~h}$ handheld device (Garmin International, Inc., Olathe, Kansas). The slope was measured using a Suunto clinometer (Suunto Oy, Valimotie, Finland). Slope measurements were taken and averaged for each field; two or more slopes for the same field were only used on the same field if a part of the field had a noteworthy change in slope in comparison with the rest of the field.

Soil characteristics for each field were measured by taking composite samples of fifteen individual soil cores to $15.24 \mathrm{~cm}$ depth and sending them to Zamorano Agricultural University in southern Honduras for analysis. The analyses included organic matter (Walkley and Black method [14]), Ntotal as 5\% of organic matter, P, K, $\mathrm{Ca}$, and $\mathrm{Mg}$ (Mehlich 3 extractant [15]), texture (Bouyoucos method [16]), and $\mathrm{pH}(1: 1$ ratio of soil to water [17]). Fields 1, 2 and 3 of Farmer 1 each had one composite sample. Field 4 of Farmer 2 had three samples because of texture differences in the upper, middle and lower portions of the field. Field 5 of Farmer 2 had two samples because the two halves of the field were on different sides of a small hill with different slopes.

Field 1's slopes were not uniform and included slopes of $5^{\circ}$ and $3^{\circ}$ degrees. Field 2 's slope was $2.5^{\circ}$ and included 9 points under management by another farmer; the different ownership and management was not discovered until the study was underway. Field 3 was the 
most uniform of the fields with a slope of $0.5^{\circ}$. Field 4 had a slope of $3^{\circ}$. Field 5's first three points of two transects on this field had slopes of $6^{\circ}$, but the remainder of the points on those transects and the other three transects had slopes of $4^{\circ}$.

Soil moisture transects and measurement: Five permanent, random transects oriented perpendicular to the contour were established on each field. Within each transect, seven points were evenly spaced with a $2.5 \mathrm{~m}$ buffer from each stake. Transect Point 1 refers to the first and highest point on a transect. Transect Point 7, therefore, refers to the lowest point in a field for a given transect. For the purposes of this study, toposequence refers to position on the gradient from Transect Point 1 to Transect Point 7 for a given transect.

Volumetric water content measurements were taken using a Field Scout TDR 300 soil moisture meter probe (Spectrum Technologies, Inc., Plainfield, IL) at each transect point. The three fields of Farmer 1 were measured for VWC under the setting "High Clay". The two fields of Farmer 2 were measured for VWC under the standard setting. The soil moisture meter was calibrated by comparing the measured VWC and weight of soil in soil cores over the course of a month of drying [18].

Volumetric water content measurements were taken during the tillering/vegetative, panicle emergence/flowering, post-flowering/pre-maturation and maturation stages. Once the rice entered each stage, measurements were taken one day, three days and six days after the successive irrigation. This schedule was not possible for all of the fields because of irrigation scheduling conflicts.

Yield data: In the week before each farmer harvested each field, when the rice had a moisture content of approximately $10 \%-20 \%$, one square meter was harvested at each transect point (35 samples per field). All panicles were harvested, bagged, and dried for two days in the sun before being manually threshed and winnowed. Each sample was then weighed using a 2500 gram Pesola Medio-Line Spring Scale with 20 gram increments (Pesola, Inc., Kapuskasing, Ontario).

Interviews: Each farmer was interviewed using a survey approved by the Michigan Technological University Institutional Review Board. The questions addressed the challenges facing rice farmers in Honduras, methods and costs of production, land tenure, and crop preferences [18].

Statistical analyses: When appropriate, soil moisture data was analyzed for the fields of each farmer separately because different soil moisture settings on the soil moisture meter were used for the fields of Farmer 1 and Farmer 2. Otherwise, statistical analyses were performed on the entire data set. Analysis of variance (ANOVA) was used to test significance in soil moisture, slope, transect points and farmers on yield [19]. Tukey's Stu- dentized Range (HSD) was used to test the significance of differences in yields across fields, slopes and transect points. Correlations looked at slope, transect points and soil moisture at transect points for the different growth stages against yields. Results were declared significant at $\mathrm{p}<0.10$. $\mathrm{p}$ values are given throughout the results and discussion sections.

\section{RESULTS}

Because rice production is sensitive to soil moisture our primary hypothesis was that rice yield should be positively correlated with soil moisture. Soil moisture content did not have a significant effect on yields in Farmer 1's fields (Table 1). Only the first measurement, when the fields were flooded, yielded significant results of soil moisture by growth stage, but the trend was negative. On Farmer 2's fields, soil moisture content was

Table 1. Correlation between soil moisture and yield and transect variables by growth stage on Farmer 1's fields. The tested growth stage and number of days following irrigation are listed. The top value for each stage is the R-value. The value in parentheses is the p-value.

\begin{tabular}{|c|c|c|}
\hline Growth Stage & Yield & Transect Point \\
\hline \multirow[t]{2}{*}{ Vegetative 1} & -0.0321 & 0.2992 \\
\hline & -0.7449 & $\left(0.0019^{*}\right)$ \\
\hline \multirow[t]{2}{*}{ Vegetative 3} & -0.1231 & 0.3597 \\
\hline & -0.2108 & $\left(0.0002^{*}\right)$ \\
\hline \multirow[t]{2}{*}{ Panicle Initiation 1} & -0.0314 & 0.3295 \\
\hline & -0.7504 & $\left(0.0006^{*}\right)$ \\
\hline \multirow{2}{*}{ Panicle Initiation 3} & -0.0393 & 0.3449 \\
\hline & -0.6907 & $\left(0.0003^{*}\right)$ \\
\hline \multirow[t]{2}{*}{ Panicle Initiation 6} & -0.0957 & 0.2788 \\
\hline & -0.3315 & $\left(0.004^{*}\right)$ \\
\hline \multirow[t]{2}{*}{ Reproductive 1} & -0.1839 & 0.3199 \\
\hline & $\left(0.0604^{*}\right)$ & $\left(0.0009^{*}\right)$ \\
\hline \multirow[t]{2}{*}{ Reproductive 3} & -0.0812 & 0.4006 \\
\hline & -0.41 & $\left(<0.0001^{*}\right)$ \\
\hline \multirow[t]{2}{*}{ Mature 1} & -0.0804 & 0.3399 \\
\hline & -0.4152 & $\left(0.0004^{*}\right)$ \\
\hline \multirow[t]{2}{*}{ Mature 3} & -0.08 & 0.2695 \\
\hline & -0.4175 & $\left(0.0054^{*}\right)$ \\
\hline \multirow[t]{2}{*}{ Mature 6} & -0.069 & 0.3608 \\
\hline & -0.4837 & $\left(0.0001^{*}\right)$ \\
\hline
\end{tabular}

\footnotetext{
${ }^{*}=$ significant value at $\alpha=0.1$.
} 
statistically significant during the second measurement of the vegetative stage and the last two measurements during the mature stage, but these were the most unlikely stages to show an effect (Table 2). Soil moisture content by growth stage was not an important factor in explaining yield differences.

When a Tukey's Studentized Range (HSD) test was run for the transect point data for yields (Table 3), field position, as represented by transect points, significantly affected yields ( $\mathrm{p}<0.0040, \alpha=0.1)$. Yields generally increased from one point to the next downslope along the transects. The lowest points in the field, points 4-7, along each transect have higher yields than the points higher up in each field (points 1-3). The data also suggest a yield gradient because point 7 is significantly different from points 1-3.

Soil moisture content changed positively and significantly on Farmer 1's $(\mathrm{p}<0.0001)$ and Farmer 2's ( $p$ $=0.0868)$ fields based by transect point (Tables 1 and 2). As transect point increased (lower toposequential position in the field), soil moisture also increased; the lower portions of the fields were more saturated than the upper portions. For Farmer 1's fields, statistical sig-

Table 2. Correlation between soil moisture and yield and transect variables by growth stage on Farmer 2's fields. The tested growth stage and number of days following irrigation are listed. The top value for each stage is the $\mathrm{R}$-value. The value in parentheses is the p-value.

\begin{tabular}{ccc}
\hline Growth Stage & Yield & Transect Point \\
\hline Vegetative 1 & 0.1567 & 0.1508 \\
Vegetative 3 & -0.1952 & -0.2127 \\
& 0.2183 & 0.2389 \\
Vegetative 6 & $\left.0.0694^{*}\right)$ & $\left(0.0464^{*}\right)$ \\
& 0.1904 & 0.198 \\
Reproductive 1 & -0.1144 & -0.1002 \\
& -0.1121 & -0.4221 \\
Reproductive 3 & -0.5216 & $\left(0.0115^{*}\right)$ \\
& -0.079 & -0.2242 \\
Mature 1 & -0.6521 & -0.1954 \\
& 0.0906 & 0.0774 \\
Mature 3 & -0.456 & -0.5242 \\
& 0.2076 & 0.1246 \\
Mature 6 & $\left(0.0848^{*}\right)$ & -0.3042 \\
& 0.2056 & 0.2062 \\
& $\left(0.0879^{*}\right)$ & $\left(0.0868^{*}\right)$ \\
\hline
\end{tabular}

\footnotetext{
${ }^{*}=$ significant value at $\alpha=0.1$.
}

Table 3. Mean values of yield in tons per hectare for transect points for all five fields. The same letter indicates no significant difference between transect yields using Tukey's test for significant difference. Transect point 7 is significantly different than points $1-3(\mathrm{p}=0.0040, \alpha=0.1)$. A general gradient of yields is also noted down the slope. $\mathrm{N}=174$.

\begin{tabular}{cc}
\hline Transect Point & Mean Yield $\left(\mathrm{t} \cdot \mathrm{ha}^{-1}\right)$ \\
\hline 2 & $3.44^{\mathrm{a}}$ \\
1 & $3.65^{\mathrm{a}}$ \\
3 & $3.81^{\mathrm{a}}$ \\
6 & $3.96^{\mathrm{a}, \mathrm{b}}$ \\
5 & $3.96^{\mathrm{a}, \mathrm{b}}$ \\
4 & $4.01^{\mathrm{a}, \mathrm{b}}$ \\
7 & $4.59^{\mathrm{b}}$ \\
\hline
\end{tabular}

nificance changed only slightly when analyzed by growth stage and number of days after an irrigation. For Farmer 2 's fields, however, the growth stage and number of days following irrigation affected the significance of soil moisture at each transect point.

In combination, these three results imply that yield increased as one proceeded downslope, soil moisture increased as one proceeded downslope, but yield was not significantly related to soil moisture. There were several factors that did influence yields in addition to position along the slope. Slope had a weak but significant negative correlation with yields (Table 4) $(\mathrm{R}=-0.48, \mathrm{p}<$ $0.0001)$. The results are consistent with previous studies done on maize, where fields with higher slopes experienced more variation and maximum terrain slope was found to be important, but where another factor, such as nutrient availability, was found to be more important $[20,21]$. The $5^{\circ}$ and $6^{\circ}$ slopes were not included in the analysis because they had sample sizes of 3 and 6 , respectively. Slopes of $2.5^{\circ}$ and $3^{\circ}$ were statistically similar, but yields on slopes of $0.5^{\circ}$ and $4^{\circ}$ were each statistically different from yields on other slopes.

The different fields also significantly affected yields ( $\mathrm{p}$ $<0.0001$ ) (Table 5). Field was an important explanatory variable for yield for both farmer data sets. Fields 1 and 2 of Farmer 1 were statistically similar in yield. Fields 1 and 3 were also similar, but fields 2 and 3 were not. Field 2 had the lowest yields regardless of whether or not the 9 points under management by another farmer were included. Field 4 and field 5 each had yields statistically different from every other field. They were also statistically lower in yield than the three fields of Farmer 1.

This study showed no correlation between slope and soil moisture on Farmer 2's fields. The study also showed significant correlations between all but one soil moisture testing date and slope on Farmer 1's fields, but 
Table 4. Mean yields generally decreased as slopes increased. The same letter indicates no significant difference between field yields using Tukey's test for significant difference. Slope has a significant $(p<0.0001 ; \alpha=0.1)$ impact on yields. Degrees of freedom $=165 . \mathrm{N}=168$.

\begin{tabular}{cc}
\hline Slope $\left({ }^{\circ}\right)$ & Mean Yield $\left(\mathrm{t} \cdot \mathrm{ha}^{-1}\right)$ \\
\hline 0.5 & $4.87^{\mathrm{a}}$ \\
2.5 & $4.07^{\mathrm{b}}$ \\
3 & $3.93^{\mathrm{b}}$ \\
4 & $2.84^{\mathrm{c}}$ \\
\hline
\end{tabular}

Table 5. Mean values of yield in tons per hectare for each field. The same letter indicates no significant difference between field yields using Tukey's test for significant difference. Field has a significant $(\alpha=0.1$.) impact on yields as Field 3 is different from Fields 2, 4 and 5. Field 1 is different from Fields 4 and 5. Field 2 is different from Fields 3, 4 and 5. Fields 4 and 5 are each unique. Degrees of freedom $=140 . \mathrm{N}=35$.

\begin{tabular}{cc}
\hline Field & Mean Yield $\left(\mathrm{t} \cdot \mathrm{ha}^{-1}\right)$ \\
\hline 3 & $4.87^{\mathrm{a}}$ \\
1 & $4.44^{\mathrm{a}, \mathrm{b}}$ \\
2 & $4.06^{\mathrm{b}}$ \\
4 & $3.46^{\mathrm{c}}$ \\
5 & $2.75^{\mathrm{d}}$ \\
\hline
\end{tabular}

the trend was negative and unexpected [18,22]. This could have been because the individual topography of Farmer 1's three fields, the difficulty of differentiating between slopes of $2.5^{\circ}$ and $3^{\circ}$ with a clinometer, and the potential for other factors to override the importance of small differences in slope.

For Farmer 1's fields, transect point was highly correlated with soil moisture content, but yields were not (Table 1), regardless of the inclusion or exclusion of the nine points in Field 2 cultivated by another farmer. The data from Farmer 2's fields showed low correlations between soil moisture content with yields or transect points (Table 2). On both fields of Farmer 2, soil moisture content increased as transect points increased, but it did not have a large effect on the yields in either field.

\section{DISCUSSION}

\subsection{Transect Point, Soil Moisture, Slope and Erosion}

We expected soil moisture would be positively correlated with transect point; as one proceeds down the slope (with the higher numbered transect points at the bottom of the slope), one expects that soil moisture should also rise. In rain-fed systems in Laos, Vietnam and the Philippines, series of fields increased in standing water in the lower portions of mildly to medium sloped toposequences $[23,24]$. Multiple fields along a toposequence can be seen as points along a transect in the same field, but soil moisture in fields in Flores did not follow this pattern completely. Soil moisture was highly correlated with transect point across testing dates for Farmer 1's fields, but was not for Farmer 2's fields although Farmer 2's field had higher slopes than those of Farmer 1. As expected, soil moisture increased downslope on Farmer 1's fields with slopes of $0.5^{\circ}, 2.5^{\circ}$ and $3^{\circ}$, but on the fields with higher slopes, those of Farmer 2, we found little or no correlation between soil moisture and transect point. This suggests that other factors on Farmer 2's fields affected drying.

Large quantities of water, supplied cheaply by the Irrigation District of Flores, and the consequent incentive to over-water may explain why we found this discrepancy. In theory, each irrigation costs 200 lempiras (approximately US $\$ 10.58$ ) and provides $1200 \mathrm{~m}^{3} \cdot \mathrm{mz}^{-1}$ (one manzana equals $6999 \mathrm{~m}^{2}$ ), equal to $171 \mathrm{~mm} \cdot \mathrm{ha}^{-1}$, at a cost of $\$ 0.009 \mathrm{per} \cdot \mathrm{m}^{3}$. This price has been found in other parts of the world to cover the operation and maintenance costs of well-functioning irrigation districts, but it falls at the extreme low end of average values of water around the world, which range from $\$ 0.05$ to $\$ 0.90$ per $\cdot \mathrm{m}^{3}$ but are more often recorded as between $\$ 0.10$ and $\$ 0.20$ per $\cdot \mathrm{m}^{3}$ [25]. In rice production, water is perceived by farmers as more important than in other crops such as soybeans and maize because it thrives in flooded conditions, experiences water stress more easily, and transpires at a greater rate than other grains [26]. Many farmers in Flores are probably receiving over $1200 \mathrm{~m}^{3} \cdot \mathrm{mz}^{-1}$ of water because the District lacks on-field water volume meters and farmers can sometimes bribe canaleros, the workers employed to open gates between the canals and the fields, to provide extra water during irrigation. Even though farmers comment that they want more water for their fields, they are already getting irrigation water at low cost.

This dynamic may explain why transect points did not correlate with soil moisture on Farmer 2's fields. We could not collect data during the panicle initiation and flowering growth stages because he was irrigating throughout these stages. During times that he was not irrigating a field used in the study, water was still percolating from the field canals into the upper portions of the fields where the first transect points were located. Near constant irrigation by Farmer 2 probably kept the soil saturated on the upper portions of the field when, using prescribed irrigation plans, it should have been drying; this eliminated the soil moisture gradient one would have expected on highly sloping fields.

For both farmers, the slope-induced differences in soil 
moisture along transect points were likely reduced by an abnormally rainy year. For upland, rainfed systems in Asia, $200 \mathrm{~mm} \cdot \mathrm{month}^{-1}$ of precipitation is adequate for acceptable rice yields [1]. Adding precipitation during the study $\left(300 \mathrm{~mm} \cdot \mathrm{month}^{-1}\right)$ and two irrigations per month (at least $342 \mathrm{~mm} \cdot$ month $^{-1}$ ), rice fields in Flores were receiving close to $650 \mathrm{~mm} \cdot \mathrm{month}^{-1}$ in 2010 . This suggests that water was not the primary constraint to optimal yields in Flores, Comayagua. Other factors, such as soil nutrient availability, soil texture, and weeds were probably contributing to yield losses upslope. These data also suggest that the Irrigation District could allocate water more efficiently; if farmers could control for slope and apply water equally to the whole field, the Irrigation District could extend its coverage.

In rice, the absence of standing water itself can significantly decrease yields even if water stress is not noted [27]. Losses of up to $120 \mathrm{~g} \cdot \mathrm{kg}^{-1}$ are possible in fields kept at saturation levels without flooding and losses up to $400 \mathrm{~g} \cdot \mathrm{kg}^{-1}$ are possible when the soil water is allowed to drop to 10 to $30 \mathrm{kPa}$ depending on frequency and severity of the drying [5]. Despite abnormally high precipitation and inexpensive irrigation water, therefore, we expected more of an effect on yields from soil moisture in the absence of flooded conditions. Transect point positively affected soil moisture on Farmer 1's fields and affected yields generally across fields but soil moisture itself did not affect yields. We expected soil moisture to predict rice yields significantly, but the data from Flores in 2010 show that this may not always be the case.

Transect point and slope were better predictors of yield than soil moisture. Other consequences of failing to mitigate the effects of slope may explain why soil moisture was not correlated with slope and transect points on Farmer 2's fields but slope and transect point were correlated with yield. Yearly runoff on sloped fields, where no soil conservation structures exist, can transport large quantities of soil nutrients, organic matter and fine particles downslope $[28,29]$. With every increase in slope, even on gently sloping fields, fields experience large increases in soil loss from water runoff. In India, for example, marginal slopes of $0.29^{\circ}$ can experience soil losses of $3.0 \mathrm{t} \cdot \mathrm{ha}^{-1}$ while slopes of $1.72^{\circ}$ can lose 13.6 $\mathrm{t} \cdot \mathrm{ha}^{-1}$ in a given year [28]. This can increase soil fertility downslope in a given field at the expense of soil fertility upslope. Fertilizer and herbicides, moreover, are not contained upslope in this situation [30]. These factors, in the absence of soil conservation structures, increase productivity downslope at the expense of upslope productivity. If a farmer attempts to maintain high soil moisture upslope by providing increased quantities of irrigation, he can compound the problem and increase yield disparities despite successfully overcoming soil moisture limitations in upslope areas.

\subsection{Rationality and Land Tenure}

Despite disparities between yields upslope and downslope, farmers may be acting rationally. Interviews with the farmers indicated that contract issues and land tenure were important reasons why they were not using soil conservation and slope-mitigation techniques. It has been well-established that land insecurity has negative impacts on the use of soil conservation structures [31-33]. Renting land has sometimes been considered differently than insecure land ownership rights, and hypothesized to be an incentive for early adoption of soil conservation technologies [34]. However, in Honduras, hillside farmers have been reluctant to invest in organic matter technologies when they do not have guaranteed continued access to the fields [35]. In the Irrigation District of Flores, it was not in the best interest of the farmers to improve rented land. The owner of the land might want the land back if improvements increased the profitability of rice farming. At the time of the study, most contracts in the District were from six months to a year in duration. If farmers improved the land by construction of soil bunds or other soil conservation features, the owner sometimes demanded the land back or chose not to rent the land the following year; the farmers would lose their investment and access to the fields in this situation.

It was in the best interest of the farmers, therefore, to forgo using large investments in land preparation to optimize production and instead to concentrate on water and fertilizer inputs for raising yields. Water was easy to control because of its low cost. When discussing farm management, farmers stated that they were investing in fertilizers and other chemical inputs.

Scale, especially for the two farmers in this study, was also an important factor. Instead of farming intensively, they chose to farm extensively; mechanization made this possible and preferable. Other farmers paid Farmer 1 to use his five tractors and two combines to prepare and harvest their fields. Both farmers in this study were wealthier than the average farmer in the District. At 55 ha for Farmer 1 and 75 ha for Farmer 2, both farmers farmed areas much larger than the average ( $5 \mathrm{ha}$ ) in the Irrigation District. Rather than focus on making the most money out of five hectares, they both focused on farming relatively well on large areas. This decision was influenced by irrigation availability, land tenure, and the availability of machinery for land preparation and harvesting. These factors likely outweighed the importance of soil moisture and slope on the rice fields of Farmers 1 and 2 in Flores during 2010. We nevertheless observed similar management on the fields of farmers cultivating on smaller parcels, likely strengthening the argument that 
insecure land access probably played a vital role in influencing in their water management.

\section{CONCLUSIONS}

This study confirmed that slope was affecting yields in the Irrigation District of Flores in Comayagua, Honduras. The value of field studies rather than research station trials was also confirmed [36]. The results indicate that farmer concerns about tenancy may generate poor onfield water and fertilizer management that logically followed from the farming system. A research station trial would not have included tenure as a social dimension of the farm system. The field study also usefully suggested that the farmers were, contrary to the original hypotheses, over-watering the fields because of the inexpensive cost of water and the presumed value they placed on using large quantities of water when irrigating the fields. The apparent yield gradient suggested that this strategy had other consequences such as erosion and nutrient leaching. This study could not identify the factors influencing yield losses up-versus downslope.

It would be beneficial for future studies to look at larger groups of fields with disparate slopes in the Irrigation District of Flores to determine whether slope, soil moisture, erosion, fertilizer regimes or other factors are causing the yield losses upslope. Given the unstable economic climate of Honduras and the year-to-year changes in the negotiated price of rice, it would be beneficial to develop a model for determining the appropriate goals for farmers in a given year. It would be enlightening to see what it would take for the region to become more intensive in production rather than extensive, as is now the case. Furthermore, it would be useful to determine the optimal pricing of irrigation water in order to maximize regional yields and minimize soil loss through erosion.

\section{REFERENCES}

[1] De Datta, S.K. (1981) Principles and practices of rice production. John Wiley and Sons, Singapore.

[2] Bouman, B.A.M. (2001) Water-efficient management strategies in rice production. International Rice Research Notes, 26, 17-22.

[3] Yang, J. and Zhang, J. (2010) Crop management techniques to enhance harvest index in rice. Journal of Experimental Botany, 61, 3177-3189. doi:10.1093/jxb/erq112

[4] Grassi, C., Bouman, B.A.M., Catañeda, A.R., Manselli, M. and Vecchio, V. (2009) Aerobic rice: crop performance and water use efficiency. Journal of Agriculture and Environment for International Development, 103, 259270.

[5] Bouman, B.A.M. and Tuong, T.P. (2001) Field water management to save water and increase its productivity in irrigated lowland rice. Agricultural Water Management, 49, 11-30. doi:10.1016/S0378-3774(00)00128-1

[6] Gun Won, J., Soo Choi, J., Phil Lee, S., Ho Son, S. and Ok Chung, S. (2005) Water saving by shallow intermittent irrigation and growth of rice. Plant Production Science, 8, 487-492. doi:10.1626/pps.8.487

[7] de Vries, M.E., Rodenburg, J., Bado, B.V., Sow, A., Leffelaar, P.A. and Giller, K.E. (2010) Rice production with less irrigation water is possible in a Sahelian environment. Field Crops Research, 116, 154-164. doi:10.1016/j.fcr.2009.12.006

[8] Peng, S., Bouman B., Visperas, R.M., Castañeda, A., Nie, L. and Park, H.K. (2006) Comparison between aerobic and flooded rice in the tropics: Agronomic performance in an eight-season experiment. Field Crops Research, 96, 252-259. doi:10.1016/j.fcr.2005.07.007

[9] Cabangon, R.J., Castillo, E.G., Lu, G., Cui, Y.L., Tuong, T.P., Bouman, B.A.M., Li, Y., Chen, C., Wang, J.X. and Liu, X. (2001) Impact of alternate wetting and drying irrigation on rice growth and resource-use efficiency. Conference Papers, International Water Management Institute.

[10] Borell, A., Garside, A. and Shu, F.K. (1997) Improving efficiency of water for irrigated rice in a semi-arid tropical environment. Field Crops Research, 52, 231-248. doi:10.1016/S0378-4290(97)00033-6

[11] Sharma, P.K. (1989) Effect of periodic moisture stress on water-use efficiency in wetland rice. Oryza, 26, 252-257.

[12] Bouman, B.A.M, Lampayan, R.M. and Tuong, T.P. (2007) Water management in irrigated rice: Coping with water scarcity. IRRI, Los Baños, Philippines.

[13] Almedarez, H.E. (1988) Agro-climatic zones of Honduras: Volume 4 (southwest central region). Secretary of Natural Resources, Department of Hydraulic and Climate Services, Agrometeorology Section, The Office of Environmental Issues at the Municipality of San Antonio Mayors Office in the Municipality of San Antonio, Comayagua, Honduras.

[14] Walkley, A. and Black, I.A. (1934) An examination of the Degtjareff method for determining soil organic matter and a proposed modification of the chromic acid titration method. Soil Science, 27, 29-37. doi:10.1097/00010694-193401000-00003

[15] Mehlich, A. (1984) Mehlich 3 soil test extractant: A modification of the Mehlich 2 extractant. Communications in Soil Science and Plant Analysis, 15, 1409-1416. doi:10.1080/00103628409367568

[16] Bouyoucos, G.J. (1936) Directions for making mechanical analysis of soils by the hydrometer method. Soil Science, 42, 225-230. doi:10.1097/00010694-193609000-00007

[17] Burt, R. (2004) Soil survey laboratory methods manual. Natural Resources Conservation Service, USDA, Washington DC.

[18] Earnshaw, K. (2011) The effects of soil moisture, fieldscale toposequential position, and slope on yields in irrigated upland rice in Flores, Comayagua, Honduras. Mas- 
ter's Thesis, Michigan Technological University, Houghton.

[19] Steel, R.G.D. and Torrie, J.H. (1960) Principles and procedures of statistics, with special reference to the biological sciences. McGraw-Hill Book Company, New York.

[20] Kravchenko, A.N., Bullock, D.G. and Boast, C.W. (2000) Joint multifractal analysis of crop yield and terrain slope. Agronomy Journal, 92, 1279-1290. doi:10.2134/agronj2000.9261279x

[21] Kravchenko, A.N., Robertson, G.P., Thelen, K.D. and Harwood, R.R. (2005) Spatial variability: Management, topographical and weather effects on spatial variability of crop grain yields. Agronomy Journal, 97, 514-523. doi:10.2134/agronj2005.0514

[22] Dunne, T. and Leopold, L.B. (1978) Water in environmental planning. W.H. Freeman and Co., New York.

[23] Boling, A.A., Tuong, T.P., Suganda, H., Konboon, Y., Harnpichitvitaya, D., Bouman, B.A.M. and Franco, D.T. (2008) The effect of toposequence position on soil properties, hydrology and yield of rainfed lowlands in Southeast Asia. Field Crops Research, 106, 22-33. doi:10.1016/j.fcr.2007.10.013

[24] Inthavong, T., Fukai, S. and Tsubo, M. (2011) Spatial variations in water availability, soil fertility and grain yield in rainfed lowland rice: A case study from Savannakhet Province, Lao PDR. Plant Production Science, 14, 184-195. doi:10.1626/pps.14.184

[25] Perry, C.J. (2001) Charging for irrigation water: The issues and options, with a case study from Iran. International Water Management Institute, Colombo, Sri Lanka.

[26] Tanguilig, V.C., Yambao, E.B., O'Toole, J.C. and De Datta, S.K. (1987) Water stress effects on leaf elongation, leaf water potential, transpiration, and nutrient uptake of rice, maize and soybean. Plant and Soil, 103, 155-168. doi:10.1007/BF02370385

[27] Fukai, S., Inthapanya, P., Blamey, F.P.C. and Khunthasuvon, S. (1999) Genotypic variation in rice grown in low fertile soils and drought-prone, rain-fed lowland envi- ronments. Field Crops Research, 64, 121-130. doi:10.1016/S0378-4290(99)00055-6

[28] Narayana, V., Dhruva, V. and Sastry, G. (1985) Soil conservation in India. In: El-Swaify, S.A., Moldenhauer, W.C. and Andrew, L., Eds., Soil Erosion and Conservation, Soil Conservation Society of America, Ankeny, 3-9.

[29] Pimentel, D., Harvey, C., Resosudarmo, P., Sinclair, K., Kurz, D., McNair, M., Crist, S., Shpritz, L., Fitton, L., Saffouri, R. and Blair, R. (1995) Environmental and economic costs of soil erosion and conservation benefits Science, 267, 1117-1123. doi:10.1126/science.267.5201.1117

[30] Cho, J.Y. (2003) Seasonal runoff estimation of N and P in a paddy field of central Korea. Nutrient Cycling in Agroecosystems, 6, 43-52. doi:10.1023/A:1021819014494

[31] Alemu, T. (1999) Insecure land tenure regimes and soil conservation. Department of Economics, Göteborg University, Gothenburg. http://eldorado.ucol.mx/icons/bdl/arc/02.pdf.

[32] Beets, W.C. (1990) Raising and sustaining productivity of smallholder farming systems in the tropics. AgBé Publishing, Alkmaar.

[33] Soule, M.J., Tegene, A. and Wiebe, K.D. (2000) Land tenure and the adoption of conservation practices. American Journal of Agricultural Economics, 82, 993-1005. doi:10.1111/0002-9092.00097

[34] Polson, R.E. and Spencer, D.S.C. (1991) The technology adoption process in subsistence agriculture: the case of cassava in southwestern Nigeria. Agricultural Systems, 36, 65-78. doi:10.1016/0308-521X(91)90108-M

[35] Arellanes, P.G. (1994) Factors influencing the adoption of hillside agriculture technologies in Honduras. Master's Thesis, Cornell University, Ithaca.

[36] Satterlee, B.M., Yemefack, M. and Orr, B.D. (2009) Maize yield and soil property responses to Entada abyssinica (Steud. ex A. Rich.) cuttings in the Adamawa Lowlands, Cameroon. Journal of Food, Agriculture, and Environment, 7, 192-196. 